Sustainability, Agri, Food and Environmental Research 4(3), 2016: 16-39

ISSN: 0719-3726

\title{
Osteoartritis en equinos: descripción, diagnóstico y alternativas terapéuticas
}

\section{Osteoarthritis in Horses: Description, Diagnosis and Therapeutic Alternatives}

\author{
Eduardo Jara \& Felipe Corrêa* \\ Universidad Andres Bello, Facultad de Recursos Naturales, Escuela de Medicina Veterinaria. \\ * Autor de correspondencia: felipe2983@gmail.com
}

\section{RESUMEN}

La osteoartritis es una enfermedad degenerativa articular que corresponde a una de las más comunes causas de cojera en el equino, con grandes pérdidas económicas y problemas de bienestar animal a causa del dolor. El cartílago articular juega un rol central en la patología, sin embargo, el hueso subcondral y membrana sinovial juegan un rol crucial en la atenuación de fuerzas y lubricación articular. La membrana sinovial es una fuente importante de citoquinas inflamatorias y enzimas degradadoras de matriz que desencadenan la cascada degenerativa de la osteoartritis aumentando el daño en el cartílago articular, esto en conjunto con alteraciones en la estructura del hueso subcondral aumentan el daño. Existen diversos métodos diagnósticos siendo el más común la radiografía, sin embargo no es el más eficiente debido a la falta de correlación con la clínica de la enfermedad, los biomarcadores pueden llevar a un método diagnóstico temprano el cual permite un tratamiento temprano de la enfermedad. Los tratamientos para osteoartritis se enfocan en recuperar la lubricación articular y reducir la inflamación sinovial siendo más comúnmente utilizados los cortico esteroides, AINES y hialuronato para esta finalidad, nuevas propuestas terapéuticas conocidas como terapias regenerativas pueden favorecer la reparación del cartílago.

Palabras clave: osteoartritis, cartílago articular, enzimas de degradación, tratamiento

\section{SUMMARY}

Osteoarthritis is a degenerative joint disease that corresponds to one of the most common causes of lameness in horses with large economic losses and animal welfare problems because of pain. Articular cartilage plays a central role in the pathology; however, subchondral bone and synovial membrane play a crucial role in mitigating forces and joint lubrication. The synovium is an important source of inflammatory and matrix degrading trigger the cascade of degenerative osteoarthritis increasing damage to the articular cartilage cytokines enzymes, this in conjunction with alterations in the structure of subchondral bone increases the damage. There are several diagnostic methods being the most common radiography, however it is not the most efficient due to the lack of correlation with clinical disease, biomarkers may lead to a diagnostic method early which allows early treatment of the disease. Treatments for osteoarthritis focus on recovering articulate and reduce synovial inflammation most commonly used cortico-steroids, NSAIDS and hyaluronate for this purpose, new forms of treatment known as regenerative therapies may promote cartilage repair being lubrication. 
Sustainability, Agri, Food and Environmental Research 4(2), 2016: 16-37

ISSN: 0719-3726

Keywords: osteoarthritis, articular cartilage degrading enzymes, treatment

\section{INTRODUCCIÓN}

Las enfermedades articulares son causas comunes de claudicación en el caballo. Este problema puede ser causado por diversos factores tales como traumatismo constante, inestabilidad articular, infección y alteraciones de osificación endocondral, entre otros. De todas las enfermedades músculoesqueléticas, los problemas articulares se posicionan, dependiendo de la disciplina ecuestre, invariablemente en el primer o segundo lugar (después de alteraciones tendíneas) como causa de disminución del rendimiento (Weeren, 2014). Si la causa inicial no es diagnosticada y tratada a tiempo, se produce un irreversible daño del cartílago articular generando como consecuencia, osteoartritis (OA).

La osteoartritis se caracteriza como una condición progresiva y de permanente deterioro del cartílago articular, con alteraciones en el hueso subcondral y tejidos blandos de la articulación (Maninchedda et al, 2015). Estudios en cadáveres demuestran que el 60 a $70 \%$ de las personas entre 60 a 70 años evidencian OA en sus rodillas (Kim, 2002). Según Oke y McIlwraith (2010), en el equino, esta enfermedad corresponde aproximadamente al $60 \%$ de los problemas de claudicación.

Osteoartritis es una de las enfermedades más debilitantes y prevalentes que afectan al equino y posee un notable impacto económico en la industria equina (Frisbie et al, 2013). El costo médico y quirúrgico de cojeras relacionadas a OA fue mayor a 700 millones de dólares dentro de estados unidos en 1998 (King et al, 2012). Esta enfermedad afecta las articulaciones diartrodiales y es el resultado de la interacción de numerosos mecanismos complejos y procesos biológicos (Oke y McIlwraith, 2010). El inicio insidioso de la enfermedad y la inherentemente lenta regeneración del cartílago convierte a la OA una de las mayores plagas de la industria equina produciendo severos problemas de bienestar animal (Weeren, 2014).

\section{Anatomía y fisiología articular}

Una articulación es un órgano compuesto por hueso subcondral, cartílago, cápsula articular y líquido sinovial, con un aporte sanguíneo local, inervación, intercambio de fluidos que funciona para mantener la homeostasis articular y producir locomoción (Bertone, 2008). La función de una articulación sinovial depende directamente de la anatomía normal y función celular apropiada de cada uno de sus componentes (Frisbie, 2012). Las articulaciones deben satisfacer desafiantes demandas y a veces incluso contradictorias. Deben absorber y transmitir las fuerzas generadas por la locomoción al igual que el esqueleto óseo, además deben permitir el deslizamiento de un hueso sobre otro (Weeren, 2014).

\subsection{Hueso subcondral}

El hueso subcondral soporta el cartílago y está conectado con él a través de una capa de cartílago calcificado. Típicamente, el hueso subcondral se compone de una capa de hueso compacto directamente adyacente a la capa de cartílago calcificado y un hueso trabecular a gran distancia de la cavidad articular. Se ha observado que el hueso trabecular es aproximadamente 10 veces más deformable que el hueso compacto (Frisbie, 2012). Esta conformación posee consecuencias mecánicas: el plato subcondral compacto provee un soporte firme, pero es rígido, mientras que el componente trabecular provee algo de elasticidad. El hueso subcondral, a diferencia del cartílago articular, es altamente vascularizado y tiene bien desarrollado el aporte nervioso, lo que juega un rol importante en la percepción del dolor en enfermedades articulares (Weeren, 2014).

\subsection{Cartílago Articular}

El cartílago articular tiene un importante rol en la transmisión y atenuación de fuerzas generadas por la locomoción (Weeren, 2014). El cartílago está compuesto de agua, colágeno y proteoglicanos que están presentes en proporciones de $65 \%$ a $80 \%, 10 \%$ a $30 \%$ y $5 \%$ a $10 \%$ de su peso, respectivamente (Caron, 2011), mientras que el contenido de condrocitos del cartílago articular se encuentra entre $1 \%$ a $12 \%$ del 
volumen del cartílago (Frisbie, 2012). El cartílago hialino es avascular, aneural y alinfático. Es por esto que depende nutricionalmente a través de la difusión desde el líquido sinovial. Debido a que el cartílago articular es aneural, las lesiones restringidas al cartílago son indoloras, y la inervación del hueso subyacente y tejidos blandos periarticulares son responsables de la información dolorosa. El cartílago es liso, resistente al desgaste, lo que permite el movimiento casi sin fricción y también proporciona un método por el cual la carga de compresión y fuerza se transmiten al hueso subcondral (Johnston, 1997).

\subsubsection{Colágeno}

Las fibras de colágeno proveen un soporte estructural para la matriz de cartílago. El colágeno tipo II es la forma predominante de colágeno en el cartílago articular, presente en un $90 \%$ de la red fibrilar y la mitad del peso seco del cartílago, este es producido por los condrocitos el cual durante el crecimiento sufre una significativa degradación y síntesis de fibras la cual se vuelve limitada en la adultos (Caron, 2011).

\subsubsection{Proteoglicanos}

Por definición, los proteoglicanos están compuestos por moléculas consistentes de proteína y glicosaminoglicanos (GAGs) (Caron, 2011). Los proteoglicanos comprenden la mayoría de la MEC que no es colágeno. Los glicosaminoglicanos más comunes del cartílago articular son condroitin-6-sulfato y el keratan-sulfato (McIlwraith, 2004). La combinación de los polianiones naturales de los glicosaminoglicanos y el exceso de moléculas en la matriz de cartílago, comparado con la solución externa resultan en un gradiente osmótico que contribuye a las propiedades hidrofílicas de los proteoglicanos (Johnston, 1997). La retención de agua por los proteoglicanos dentro de la MEC crea una presión de tumefacción y turgencia que es integral a la función normal del cartílago (Johnston, 1997). Importante, estas cadenas de glicosaminoglicanos poseen una alta carga negativa que atrae 50 veces su peso en agua. Esto hidrata altamente la matriz del cartílago haciéndolo compresible, otorgándole la habilidad de disipar las cargas (Caron, 2011).

El hialuronato es un componente importante de la matriz de cartílago articular y liquido sinovial. El hialuronato encontrado en la MEC es producido por condrocitos, mientras que el hialuronato encontrado en el fluido sinovial es producido por los sinoviocitos tipo B. El hialuronato del líquido sinovial funciona como lubricante y como barrera. La función del hialuronato como una barrera se debe a la configuración estérica que forma la molécula hidratada. El hialuronato es un lubricante limitante para tejidos suaves pero aparentemente no tiene rol en la lubricación cartílago sobre cartílago. (Johnston, 1997).

\section{Membrana y líquido sinovial}

La cavidad sinovial es definida por una cápsula articular que involucra la articulación completa. La cápsula articular puede ser dividida en tres capas: una capa de revestimiento sinovial (íntima sinovial o membrana sinovial), una capa subsinovial (sub íntima), y la cápsula fibrosa. La población celular de la capa íntima está basada en 2 funciones básicas: fagocitosis y secreción de proteínas (Frisbie, 2012). La capa más interna es la membrana sinovial la cual se compone principalmente de tres tipos celulares. Las células tipo A de origen macrófago; células tipo B derivado de fibroblastos; y células tipo C que son una forma intermedia entre A y B. Las más abundantes son las células tipo B, que sintetizan una variedad importante de macromoléculas, incluyendo colágeno y hialuronato (Caron, 2011). Los sinoviocitos son responsables de la secreción de una diversa gama de proteínas que contribuyen a las propiedades de la membrana sinovial, como la composición del líquido sinovial, estos componentes incluyen hialuronato, colágeno, lubricina, pro-matriz metaloproteinasa, interleuquinas, y eicosanoides como prostaglandinas E2 (Frisbie, 2012). 
3. Lubricación de la articulación

Existen 2 sistemas de lubricación aceptados por la comunidad científica: modelo elastohidrodinámico que funciona a altas cargas de peso, y un sistema limitante que funciona a bajas cargas de peso (Frisbie, 2012).

\subsection{Lubricación elastohidrodinámica}

La lubricación elastohidrodinámica, es aceptada como la mejor representación de la lubricación del cartílago articular, se basa en la atracción de agua por moléculas de agrecanos en la superficie articular porosa, cuando se aplica una carga o presión a la superficie, el agua se exprime de la superficie articular y es interpuesta entre las superficies de apoyo, luego el fluido es reabsorvido al disminuir la carga (Frisbie, 2012).

\subsection{Lubricación limitante}

La lubricación limitante es realizada por moléculas especializadas incluyendo lubricina (glicoproteina de origen sinovial) y hialuronato (Caron, 2011). Estas moléculas previenen la adhesión y abrasión de las dos superficies cartilaginosas y es independiente de las propiedades fisicas del lubricante o superficie de contacto (Frisbie, 2012). Se ha llegado a la conclusión que la lubricación proporcionada por una película de líquido, esta influenciada por la viscocidad del lubricante. La viscocidad del líquido sinovial también tiene una considerable importancia en la reducción de la fricción en bajas cargas sobre las superficies articulares y la digestion de la fricción en bajas cargas sobre las superficies articulares (McIlwraith, 2004).

\section{Osteoartritis}

Según OARSI (Osteoarthritis Research Society International) OA en humanos se define como, "un desorden que involucre articulaciones móviles caracterizados por estrés celular y degradación de la matriz extracelular iniciada por micro y macro daño que activa respuestas reparativas que incluyen vías pro inflamatorias de inmunidad innata. La enfermedad se manifiesta primero por una degeneración molecular (metabolismo anormal de tejido articular) seguido por degradación anatómica y/o fisiológica (caracterizado por degradación de cartílago, remodelación ósea, formación de osteofitos, inflamación articular y perdida de la función articular normal), que culmina en enfermedad” (Kraus et col, 2015).

El promedio anual de costos económicos asociados a OA por paciente fueron estimados aproximadamente en $\$ 10.000$ dólares pudiendo llegar hasta los $\$ 15.000$, considerando los costos directos e indirectos de la patología en caballos fina sangre carrera (Oke, 2010).

La articulación metacarpo falángica corresponde a la articulación más comúnmente afectada por OA espontánea en caballos de carrera, seguido por las articulaciones del carpo, ambas articulaciones presentan superficies articulares que pueden rápidamente desarrollar erosión y usualmente están asociadas a fragmentos osteocondrales (McIlwraith, 2015).

\subsection{Etiopatogenia de Osteoartritis}

En OA el balance anabólico y catabólico del cartílago articular se encuentra comprometido y la degradación predomina por sobre la capacidad de reparación (McIlwraith, 2015). La etiología de OA, puede ser clasificada en base a los factores que influyen en la homeostasia de la articulación y contribuir a cambios degenerativos de esta (Mc Donald L. 2010). Tres mecanismos patogénicos son hipotetizados en el desarrollo de OA (Caron, 2011).

*Cartílago normal sometido a fuerzas biomecánicas anormales

El primer mecanismo presenta una articulación con un cartílago normal sometido a fuerzas biomecánicas anormales, como trauma, malos aplomos, desbalance de cascos, displasia articular, o 
elevada condición corporal (Riggs, 2006). Esta es la hipótesis más popular para explicar la patogénesis de OA, la matriz o células son dañadas por las fuerzas biomecánicas anormales resultando en alteración del metabolismo de condrocitos, llevando a la liberación de enzimas proteolíticas que causan la fibrilación del cartílago y ruptura de la red de proteoglicanos (Caron, 2011).

*Cambios físicos del hueso subcondral

El segundo mecanismo propuesto corresponde a cambios físicos del hueso subcondral. En esta hipótesis de OA, estrés mecánico normal resulta en micro fracturas del hueso subcondral y epífisis trabecular (Ley y col 2009), sin embargo, cuando estas fracturas son recurrentes en un corto periodo de tiempo, y superan la capacidad óptima de recuperación del hueso, puede ocurrir la remodelación de este. La remodelación del hueso incluye esclerosis del plato subcondral y hueso trabecular con una reducción de la capacidad de absorber cargas fisiológicas (Caron, 2011).

*Defectos del cartílago articular frente a fuerzas biomecánicas anormales

Una tercera hipótesis propuesta indica un defecto fundamental en el cartílago con fuerzas biomecánicas anormales. En esta vía una matriz de cartílago biomecánicamente defectuoso falla bajo cualquier carga incluso normal. OA atribuido a una matriz de cartílago defectuosa no ha sido identificada en el equino (Caron, 2011). Un ejemplo de propiedades biomecánicas anormales es un defecto genético que ha sido descrito en humanos correspondiente a un colágeno tipo 2 inestable a cargas normales de la articulación (Frisbie, 2012).

Otros factores etiológicos mencionados por Schlueter y Orth, 2004:

- Inmovilización: la reducción de la carga o inmovilización, a causa de la falta del ejercicio, puede llevar a atrofia o degeneración del cartílago articular debido a la disminución en el contenido de GAGs.

- Conformación: ciertos rasgos conformacionales pueden predisponer al caballo a claudicaciones, rasgos tales como abierto de rodilla, junto de rodilla, varus/valgus de carpo llevan al animal a sobrecargar su conformación anormal de carpo y podría resultar en OA.

- Herraje: el casco del caballo debe estar balanceado para absorber las vibraciones de alto impacto cuando es expuesto a traumas repetitivos de la competencia, es por esto que una orientación alterada del casco, que podría ser el resultado de un inadecuado despalme y herraje, influencia la presión intra-articular en articulaciones con OA.

- Edad: la avanzada edad es el factor de riesgo más significativo para desarrollar OA en humanos, sin embargo, es sabido que en los equinos $\mathrm{OA}$ se desarrolla en animales jóvenes de aproximadamente de 2 años debido al temprano inicio de su vida deportiva. El entrenamiento a temprana edad puede participar del daño a las articulaciones que son incapaces de soportar las fuerzas extremas a las que son sometidas en ejercicio.

4.1.1. Factores asociados a la degradación del cartílago

Se mencionan los siguientes factores asociados a la degradación del cartílago articular bajo condiciones de estrés normal y patológico con un cartílago alterado y normal respectivamente (McIlwraith, 2004) (Figura. $1)$. 


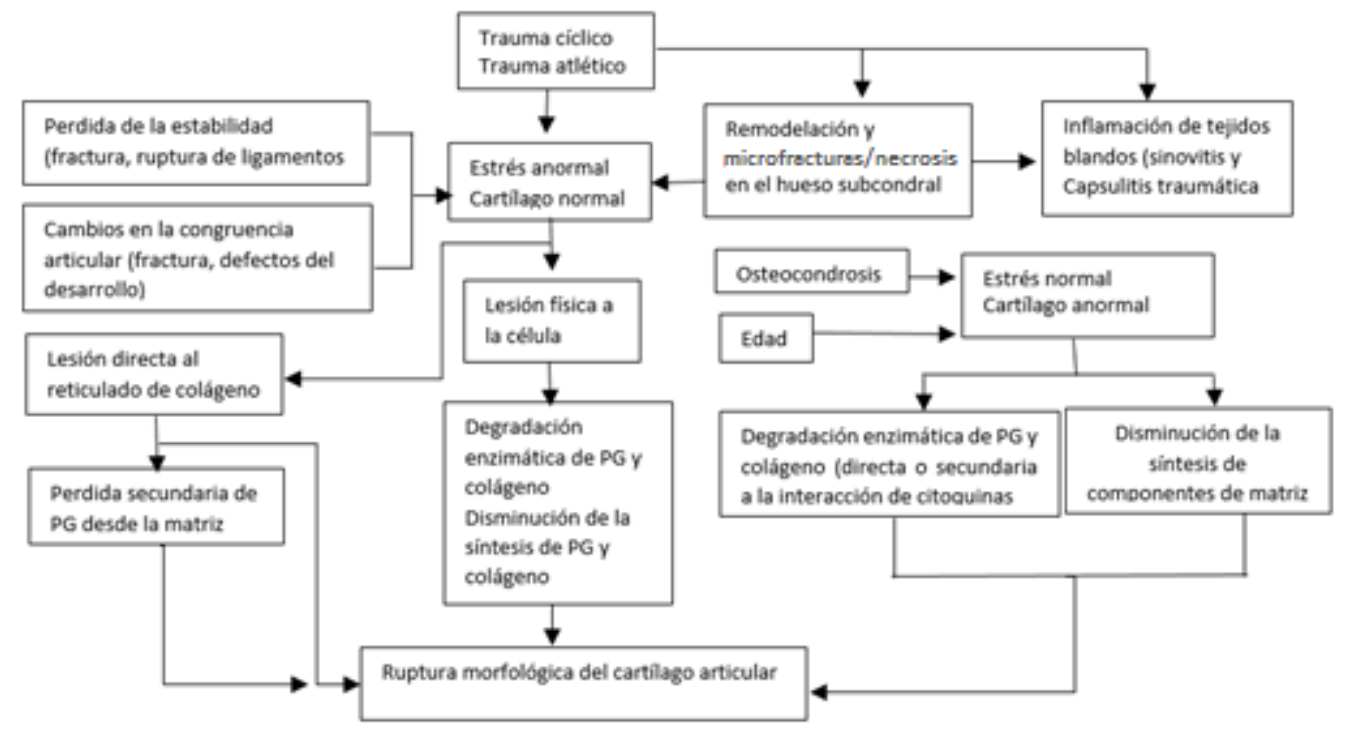

Figura. 1 Factores asociados a la degradación del cartílago articular en equinos (adaptado desde McIlwraith, 2004).

McIlwraith en 2004 sugiere que los factores mecánicos a los que el cartílago articular se encuentra normalmente expuesto in vivo son insuficientes para destruir el tejido de forma directa, pero cuando la integridad química de la matriz está comprometida, desde el punto de vista bioquímico, el daño directo puede ser posible.

A pesar de todas las posibles causas de OA, los cambios resultantes son muy similares. Básicamente estos cambios consisten en que la articulación es incapaz de mantener su propia homeostasis. Este complejo puede romperse por un trauma o luego de micro traumas repetidos, que dañen a los condrocitos y a la MEC, o bien puede deberse a la presencia de leucocitos, que estén presentes por algún proceso inflamatorio y que liberen mediadores pro-inflamatorios que destruyan la estructura del cartílago (McIlwraith 2005a).

\subsection{Mecanismos de agotamiento de la matriz de cartílago articular}

4.2.1. Rol de los condrocitos

Los condrocitos articulares son responsables de la mantención del ambiente articular mediante complejas interacciones de mediadores anabólicos y catabólicos como resultado del estímulo mecánico (Frisbie, 2012). En una articulación normal la homeostasis es mantenida por complejas interacciones entre condrocitos, citoquinas y mecanismos estimuladores. En OA los procesos catabólicos son predominantes, llevando a la depleción de matriz, pérdida progresiva de la masa cartilaginosa y las propiedades visco elásticas resultan ineficientes para soportar la carga normal, Ocurriendo la fisura y separación del cartílago, remodelación del hueso y tejidos blandos articulares (Caron, 2011).

Al ocurrir degradación del cartílago, la sobre regulación de la síntesis de proteoglicanos de los condrocitos es insuficiente para compensar la degradación del cartílago, de esta manera la concentración de la matriz disminuye progresivamente. La degradación del colágeno acompaña la pérdida de proteoglicanos manifestándose como fibrilación superficial del cartílago. Se cree que enzimas proteolíticas sintetizadas por los condrocitos son los mayores mediadores de la depleción de la matriz. Enzimas como proteinasa aspártica, proteinasa cisteína, proteinasa sérica, y metaloproteinasa contribuyen a la degradación del cartílago (Caron, 2011). 


\subsubsection{Sinovitis y Capsulitis}

El rol de la membrana sinovial y la cápsula articular en la patogénesis de OA a menudo no se ha enfatizado, debido al mayor enfoque en el cartílago y hueso articular (Frisbie, 2012). En varias especies se ha mostrado que los sinoviocitos son una abundante fuente de mediadores inflamatorios y enzimas de degradación implicadas en la degradación del cartílago, incluyendo prostaglandinas, citoquinas y metaloproteinasas de matriz (Caron, 2011).

La sinovitis puede resultar de un continuo y repetitivo trauma de forma discreta. Aunque la membrana sinovial no posee propiedades biomecánicas estabilizadoras, responde al daño a través de vías celulares y enzimáticas (Caron, 2011). Algunas lesiones pueden afectar la difusión a través de la membrana sinovial y otras tendrán un efecto primario en el metabolismo de los condrocitos (McIlwraith, 2004). Es por esto que el daño mecánico a los sinoviocitos produce la liberación de mediadores involucrados en la enfermedad articular, estos mediadores incluyen: interleuquina 1 (IL-1), Factor de necrosis tumoral (TNF), Metaloproteinasas (MMP) y agrecanasas, Prostaglandinas E2 (PGE2) y radicales libres (McIlwraith, 2005a).

Se ha sugerido que la alta presión intraarticular en las articulaciones lesionadas asociadas con efusión podría impedir el flujo de sangre a través de los capilares sinoviales. Esto podría disminuir la tensión de oxígeno y causar daño por reperfusión (McIlwraith, 2004).

La patogénesis de OA se caracteriza por la superposición de complejos mecanismos moleculares, resultando en el daño al tejido compresible de la articulación (Carmona y col 2009). Para facilitar el entendimiento de la patología es importante conocer las moléculas involucradas en este proceso.

\subsubsection{Enzimas degradadoras de matriz}

Las metaloproteinasas (MMP) son consideradas por jugar el mayor rol en la degradación de la matriz del cartílago en OA puesto que este grupo de proteinasas son capaces de digerir la mayoría de los componentes de la matriz extracelular (Caron, 2011). Estas enzimas pertenecen a un grupo de endopeptidasas dependientes de zinc y pueden ser secretadas por sinoviocitos, condrocitos, macrófagos y neutrófilos (Carmona y col 2009). Las MMP están presentes en altas concentraciones en el cartílago enfermo, y su distribución topográfica y concentración en el cartílago está correlacionada con la severidad histológica de la lesión (Caron, 2009). Las mayorías de las MMP descritas que se han relacionado a OA incluyen la colagenasa 1 (MMP-1), colagenasa 2 (MMP-8), colagenasa 3 (MMP-13), estromelisina 1 (MMP-3) y dos gelatinasas (MMP-2 y MMP-9) (Frisbie, 2012) (Tabla 1).

La MMP-1 también conocida como colagenasa intersticial o tisular, es capaz de romper las moléculas de colágeno tipo 2 intactas, La colagenasa neutrofilica humana (MMP-8) está relacionada a leucocitos polimorfonucleares almacenadas en gránulos, la MMP-13 ha mostrado ser mucho más agresiva en la degradación de colágeno tipo 2, clivando 10 veces más rápido que MMP-1, también se ha observado que MMP son producidas en gran cantidad estimulada por IL-1 y FNT (McIlwraith, 2004).

Las MMP son inhibidas por dos inhibidores tisulares: TIMP-1 y TIMP-2, estos inhiben a todas las MMP formando un complejo 1:1 entre enzima e inhibidor. El inhibidor TIMP se encuentra en diversos tejidos, puede ser el inhibidor más importante del cartílago articular, la deficiencia de TIMP en caballos con OA en relación con MMP se considera importante en la patología (Mcllwraith, 2004).

\subsubsection{Citoquinas}

En OA existe un gran número de citoquinas catabólicas que participan en el desarrollo de la enfermedad algunas compartidas con el ser humano (Tabla 2). En OA son importantes las proteínas pro inflamatorias, como IL-1 y TNF- $\alpha$. Los receptores en condrocitos para IL-1 y TNF- $\alpha$ están sobre expresados en el cartílago con OA, la activación de estos receptores tiene severos efectos deletéreos en el metabolismo de los condrocitos (Caron, 2011). Estas citoquinas inducen a células articulares como condrocitos y células sinoviales a producir otras citoquinas como IL-8, IL-6 (Fernandez et al, 2002). Se ha 
demostrado que TNF- $\alpha$ estimula la actividad de IL-1, ambas moléculas promueven la producción de MMP, óxido nítrico y prostaglandinas $\mathrm{E}_{2}$, además inhiben agrecanos y la síntesis de colágeno tipo 2 (Frisbie, 2012). Además, La IL-1 también contribuye en eventos proliferativos, la formación de osteofitos en parte es causada por la estimulación de células tipo osteoblasto por la IL-1 (Caron, 2011).

Tabla 1. Muestra las diferentes metaloproteinasas, su función e inhibidores

\begin{tabular}{|c|c|c|c|}
\hline Enzima & Numero de MMP & Función & Numero de TIMP \\
\hline \multicolumn{4}{|l|}{ COLAGENASAS } \\
\hline $\begin{array}{l}\text { Colagenasa intersticial } \\
\text { (colagenasa } 1)\end{array}$ & MMP-1 & $\begin{array}{l}\text { Colágeno II y X, denatura tipo } \\
\text { II, agreganos y proteínas de } \\
\text { unión }\end{array}$ & $\begin{array}{l}\text { TIMP-1 > TIMP- } \\
2\end{array}$ \\
\hline Colagenasa neutrofilica & MMP-8 & $\begin{array}{l}\text { Colágeno II, agreganos, } \\
\text { proteínas de unión }\end{array}$ & TIMP-1, TIMP-2 \\
\hline Colagenasa 3 & MMP-13 & $\begin{array}{l}\text { Colágeno II,IV,IX,X; } \\
\text { agrecanos, fibronectina }\end{array}$ & TIMP-3 \\
\hline \multicolumn{4}{|l|}{ ESTROMELISINAS } \\
\hline Estromelisina 1 & MMP-3 & $\begin{array}{l}\text { Agrecano, fibronectina, } \\
\text { colágeno II denaturado, }\end{array}$ & $\begin{array}{l}\text { TIMP-1 > TIMP- } \\
2\end{array}$ \\
\hline Estromelisina 2 & MMP-10 & $\begin{array}{l}\text { colágenos IV, IX, X, XI; } \\
\text { procolagenos; proteína de } \\
\text { union; decorina; elastinas; } \\
\text { laminina y función de } \\
\text { estromelisina } 1\end{array}$ & TIMP-3 \\
\hline \multicolumn{4}{|l|}{ GELATINASAS } \\
\hline Gelatinasa A & MMP-2 & $\begin{array}{l}\text { Colágeno II denaturado, } \\
\text { colágeno X y XI, elastina }\end{array}$ & TIMP-2 > TIMP1 \\
\hline Gelatinasa B & MMP-9 & $\begin{array}{l}\text { Agreganos, fibronectina, } \\
\text { colágeno IX y XI, } \\
\text { procolageno, proteína de } \\
\text { unión, decorina, elastina }\end{array}$ & --- \\
\hline
\end{tabular}

Se ha propuesto que IL-1 $\beta$ es uno de los más importantes citoquinas catabólicas involucradas en OA, promueve la expresión de un importante factor llamado factor nuclear $\kappa-\beta$ e inhibe las vías metabólicas en los condrocitos que son usadas para reparar la MEC dañada y disminuye la expresión de los inhibidores naturales de MMP conocidos como TIMPs (inhibidor tisular de metaloproteinasas) (Carmona y col 2009).

También se han observado citoquinas moduladoras o reguladoras, como IL-4, IL-10 y IL-13, su acción balancea o modula las citoquinas pro inflamatorias, inhiben la síntesis de IL-1, promueven la síntesis de inhibidores naturales, específicamente TIMP y IL-1Ra (Frisbie, 2012). Además, existen citoquinas que promueven la cascada anabólica del metabolismo del cartílago como son el factor de crecimiento tipo insulina (IGF) y el factor transformador de crecimiento (TGF) que juegan un rol en OA (Frisbie, 2012).

\subsubsection{Prostaglandinas}

Se ha observado que prostaglandina $\mathrm{E}_{2}\left(\mathrm{PGE}_{2}\right)$ causa inflamación sinovial y puede contribuir a la degradación de la matriz del cartílago y la erosión de cartílago y hueso. Las prostaglandinas regulan la la expresión de citoquinas y liberación de MMPs que en células articulares es regulada por prostaglandinas 
de la serie $\mathrm{E}$ (Caron, 2011). Las $\mathrm{PGE}_{2}$ tienen un importante efecto en el proceso inflamatorio debido a que promueven la dilatación vascular, reduce el umbral del estímulo doloroso, facilita la regulación de activador de plasminógeno y promueve la degradación de proteoglicanos (Carmona y col 2009). La PGE 2 es liberada desde los condrocitos a partir de la estimulación de estas células por IL-1 y TNF- $\alpha$ (McIlwraith, 2004).

Tabla 2. Citoquinas catabólicas involucradas en la patogénesis de OA compartidas entre equinos y humanos.

\begin{tabular}{|c|c|c|c|c|c|}
\hline Citoquinas & Especie & Fuente natural & Estimulo & Inhibición & $\begin{array}{l}\text { Mecanismo de } \\
\text { acción }\end{array}$ \\
\hline IL-1 & $\begin{array}{l}\text { Equino } \\
\text { humano }\end{array}$ & $\begin{array}{l}\text { Condrocitos, } \\
\text { sinoviocitos, } \\
\text { macrófagos, } \\
\text { linfocitos, } \\
\text { Fibroblastos }\end{array}$ & $\begin{array}{l}\text { Trauma, } \\
\text { infección }\end{array}$ & $\begin{array}{l}\text { IL-1ra, IL-4, IL- } \\
\text { 10, IL-11, IL-13, } \\
\text { TGF- } \beta, \text { PGE } 2\end{array}$ & $\begin{array}{l}\wedge \mathrm{MMPs}, \wedge \mathrm{PGE}_{2}, \\
\wedge \mathrm{COX}-2, \wedge \mathrm{NO}, \wedge \\
\text { TNF, IL-6, } \vee \\
\text { TIMPs, } \vee \text { síntesis } \\
\text { MEC }\end{array}$ \\
\hline IL-6 & $\begin{array}{l}\text { Equino } \\
\text { humano }\end{array}$ & $\begin{array}{l}\text { Condrocitos, } \\
\text { sinoviocitos, } \\
\text { macrófagos, } \\
\text { linfocitos, } \\
\text { Fibroblastos }\end{array}$ & $\begin{array}{l}\text { IL-1 } \\
\text { (equino) }\end{array}$ & $\begin{array}{l}\text { IL-4, IL-10, IL- } \\
\text { 13, sIL-6R }\end{array}$ & $\begin{array}{l}\wedge \text { proteinas de fase } \\
\text { aguda, } \wedge \\
\text { proliferación de } \\
\text { linfocitos } \mathrm{T} \text { y } \mathrm{B} \text { y } \\
\text { fibroblastos, } \wedge \\
\text { inhibidor de serin } \\
\text { proteasa }\end{array}$ \\
\hline TNF- $\alpha$ & $\begin{array}{l}\text { Equino } \\
\text { humano }\end{array}$ & $\begin{array}{l}\text { Condrocitos, } \\
\text { sinoviocitos, } \\
\text { macrófagos, } \\
\text { linfocitos, } \\
\text { Fibroblastos }\end{array}$ & $\begin{array}{l}\text { Trauma, } \\
\text { infección, } \\
\text { IL-1 }\end{array}$ & $\begin{array}{l}\text { IL- } 4, \text { IL-10, IL- } \\
11, \text { IL-13, TGF- } \beta \text {, } \\
\text { sTNFRs }\end{array}$ & $\begin{array}{l}\wedge \mathrm{PGE}_{2,} \wedge \mathrm{COX}-2, \wedge \\
\mathrm{NO}, \wedge \mathrm{IL}-1 \text { y otras } \\
\text { citoquinas } \\
\text { catabólicas, } \\
\vee \mathrm{TIMPs}, \\
\vee \text { síntesis de MEC }\end{array}$ \\
\hline
\end{tabular}

IL, interleuquina; ILra, receptor antagonista de interleuquina; TGF, factor necrosis tumoral; PGE, prostaglandinas; sIL, receptor soluble de interleuquina; MEC, matriz extra celular; COX, ciclooxigenasa; MMP, metaloproteinasa; ${ }^{\wedge}$, aumento; $\vee$, disminuye (Carmona y col 2009).

\subsubsection{Neuropéptidos}

Se ha señalado que el sistema nervioso tiene un posible rol en la patogénesis de la enfermedad. La percepción sensitiva de los nervios articulares no solo entrega información del dolor, sino que además da lugar a la liberación de neurotransmisores con un potencial papel inflamatorio, puesto que la exposición a sustancia $\mathrm{P}$ y otros neuropéptidos causan la liberación de citoquinas tales como IL-1 y IL-6 y TNF (McIlwraith, 2004).

\subsection{Dolor articular}

El dolor articular se manifiesta generalmente como una claudicación que es el resultado de la inflamación articular, exposición del hueso subcondral, neo vascularización, neo inervación y el incremento de la presión intramedular ósea (Carmona et al, 2009). El cartílago es aneural, por lo que mientras su rol en la patogénesis de OA es central, este no puede ser la fuente del dolor. Por el contrario, 
el hueso subcondral, periostio, membrana sinovial, ligamentos y cápsula articular son ricamente inervados y contienen terminales nerviosas que podrían ser la fuente del estímulo nociceptivo (Dieppe et al, 2005). Los Nervios sensoriales son conocidos por responder a estímulos mecánicos como el estiramiento y mediadores químicos tales como quininas y Neuropéptidos (sustancia P) y se ha observado que estimulan las fibras dolorosas directamente, $\mathrm{PGE}_{2}$ y IL-1 sensibilizan fibras volviéndolas más reactivas a estímulos mecánicos posteriores (Frisbie, 2012).

\subsection{Formación de osteofitos}

Además del proceso central de degradación del cartílago articular en la osteoartritis, se produce un segundo proceso patológico de proliferación de nuevo cartílago y hueso en la periferia de las articulaciones denominado osteofitosis (McIlwraith, 2004). Los osteofitos pueden limitar el movimiento y representar una fuente de dolor articular, su formación ha sido interpretada como una adaptación de la articulación a biomecanismos alterados de osteoartritis (Hashimoto et al, 2002). Estas formaciones son denominadas con frecuencia osteofitos, pero el término osteocondrofitos puede ser más correcto, la formación de osteofitos puede considerarse un componente característico y una consecuencia secundaria de la osteoartritis (McIlwraith, 2004). Lo anteriormente mencionado es cuestionable puesto que según Hashimoto y col (2002) los osteofitos pueden aparecer en ausencia de otros cambios óseos, por lo que pueden no ser una manifestación de OA y no predicen la progresión radiográfica del daño articular. Van der Kraan y Van der berg (2007) apoyan la idea anterior mencionando que en modelos humanos y animales la formación de osteofitos puede ocurrir sin daño del cartílago indicando que la formación de osteofitos y OA no están relacionadas directamente, aunque la confirmación de un cartílago dañado mediante la reducción del espacio articular se ha reportado como altamente relacionada con la presencia de osteofitos (Van der Kraan y van den berg, 2007). Se ha descrito mediante un modelo equino inducido con "filipin", que la formación de osteofitos no se relacionó con una lesión cartilaginosa significativa y que seguía la misma secuencia tejido fibroso, luego cartílago y por ultimo hueso al igual que los modelos caninos (McIlwraith, 2004).

\subsection{Cambios en hueso subcondral}

Adicionalmente a la degradación mediada por la membrana sinovial del cartílago articular y daño mecánico directo, el hueso subcondral juega un rol primario en el desarrollo de la OA (McIlwraith, 2015). El hueso subcondral responde al estrés del ejercicio incrementando la formación de hueso y densidad en un intento de incrementar su fuerza y resistencia ( $\mathrm{Li}$ et al, 2013).

La remodelación del plato del hueso subcondral que es expuesto a excesivas cargas mecánicas no fisiológicas resultan en mayor rigidez ósea de una densidad no homogénea que no es eficiente en absorber la fuerza de golpe, además, sobre la mayor densidad y menor compliance ósea, la deformación fisiológica del cartílago es alterada y puede generar daño por estrés en el cartílago (Hayami et al, 2004).

En la etapa tardía de OA, la característica micro estructural del hueso subcondral presenta un aparente incremento de densidad, incremento del volumen óseo, engrosamiento del plato del hueso subcondral, incremento del grosor del trabeculado, disminución de la separación del trabeculado y espacio de medula ósea y transformación del trabeculado desde una forma de varilla a una forma de similar al plato subcondral (Li et al, 2013).

\subsection{Diagnóstico}

4.6.1. Manifestaciones clínicas

La Osteoartritis es clínicamente más frecuentemente manifestada como una lenta y progresiva cojera que puede, a menudo, ser bilateral. Esta cojera puede ser debido a (kidd, 2001):

- Dolor articular

- Disminución del rango de movimiento articular

- Variable efusión articular 


\section{- Inflamación sin efectos sistémicos}

En algunas enfermedades articulares, la localización del problema en una articulación en particular puede ser difícil, la realización de pruebas de flexión pueden ser útiles para acentuar la claudicación en un miembro. En general, las respuestas más severas a las pruebas de flexión son más confiables para ser tomadas en cuenta (Kidd, 2001). Los caballos sanos pueden mostrar una respuesta positiva en las pruebas de flexión y esta respuesta varía directamente con la presión aplicada al miembro, por lo que se debe tener cuidado al basarse en la prueba de flexión para diagnosticar claudicaciones (McIlwraith, 2004). Sin embargo, el lugar del problema se define de mejor forma con bloqueos peri neurales o intra articulares (McIlwraith, 2004).

La efusión es un factor común de OA y se manifiesta en el aspecto distal del miembro equino como una visible y palpable distención de los recesos articulares (Caron, 2011). Aunque el incremento del líquido sinovial puede ser iniciado por un evento inflamatorio articular, la efusión sinovial es en parte resultado de una permeabilidad vascular incrementada (fenómeno de ingreso) y un disminuido drenaje linfático (fenómeno de egreso) (Frisbie, 2012).

La reducción del movimiento articular puede deberse a dolor, efusión articular, espasmo y contractura de estructuras periarticulares o anquilosis fibrosa u ósea.

4.6.2. Análisis de líquido sinovial

Cambios en el contenido del líquido sinovial se observan en la mayoría de los casos de OA (Frisbie, 2012). La reducción en la viscosidad del líquido sinovial es un hallazgo frecuente en caballos con OA, particularmente en caballos con sinovitis activa (Caron, 2011). La viscosidad del líquido sinovial es resultado de la polimerización del hialuronato, en OA existe una disminución del contenido y polimerización del hialuronato resultando en una disminución de la viscosidad del líquido sinovial (Kidd, 2001). La viscosidad puede ser evaluada de forma subjetiva mediante la formación de fibras de 2,5 a $5 \mathrm{~cm}$ antes de su ruptura. La evaluación de viscosidad también puede realizarse mediante citología donde normalmente las células están dispuestas de forma acordonada, cuando disminuye la viscosidad las células se desordenan (Steel, 2008).

En combinación con la observación física del líquido sinovial que usualmente es amarillo claro libre de material floculante, la determinación de proteínas totales del líquido sinovial en laboratorio a menudo guarda relación con el grado de sinovitis y se ha correlacionado al daño del cartílago articular mediante artroscopía (Frisbie, 2012).

La examinación citológica es la parte más importante del análisis del líquido sinovial (Steel, 2008). En el análisis citológico del líquido sinovial, el análisis del conteo de leucocitos y citología provee importante información diagnóstica sobre la causa del aumento de la efusión sinovial (El-Gabalawy, 2013). Las características del líquido sinovial asociado a OA en comparación con otras enfermedades se muestran en el Tabla 3 (Caron, 2011).

\subsubsection{Diagnóstico por imagen}

4.6.3.1. Radiografía

La radiografía es el método tradicional más ampliamente usado en la evaluación de los cambios estructurales de OA. La radiografía, tiene méritos al caracterizar los cambios en el hueso que acompañan una OA crónica y puede ser usado para el diagnóstico de una enfermedad establecida (Caron, 2011). Lamentablemente existe una pobre correlación entre los signos clínicos y cambios radiográficos en OA (McIlwraith, 2005a). La mayor desventaja de la radiografía es que los cambios radiográficos pueden no estar presentes en etapas tempranas de OA que se caracteriza por la degradación del cartílago, esto puede retrasar el diagnóstico y tratamiento disminuyendo consecuentemente el pronóstico a largo plazo (Kidd et al, 2001). 
Los cambios radiográficos que pueden ser observados en la articulación afectada son los siguientes (Caron, 2011):

- Inicialmente, reducción del espacio articular, esclerosis del hueso subcondral, formación de osteofitos.

- Con el tiempo, defectos radio lúcidos en el hueso subcondral (lisis), fragmentos osteocondrales, anquilosis de la articulación.

Tabla 3. Lista de parámetros citológicos en evaluación de líquido sinovial encontrados en distintas patológicas respecto a un análisis normal y OA (Caron, 2011).

\begin{tabular}{lllll}
\hline Parámetros & Normal & Sinovitis OCD & osteoartritis & Artritis séptica \\
\hline Leucocitos totales $(\mu \mathrm{L})$ & $50-500$ & $20-250$ & $\leq 1 \times 10^{3}$ & $20-200 \times 10^{3}$ \\
Neutrófilos $(\%)$ & $<10$ & $<10$ & $<15$ & $>90$ (cambios \\
Células mononucleares $(\%)$ & $>90$ & $>90$ & $>85$ & 50 \\
Proteínas totales $(\mathrm{g} / \mathrm{dL})$ & $0.8-2.5$ & $0.8-3.0$ & $0.8-3.5$ & $4.0-8.0$ \\
\hline
\end{tabular}

Tabla 4. Cambios radiológicos presentes en osteoartritis.

$$
\text { Cambios Radiológicos presentes en osteoartritis }
$$

Cambios radiológicos

Osteofito peri articular

Reducción asimétrica del espacio articular

Radio opacidad subcondral incrementada

Área radio lucida subcondral

Cuerpos osteocondrales

Anquilosis/remodelación avanzada

\section{Mecanismo patogénico}

Osificación endocondral ocurre en los márgenes óseos, es de etiológica desconocida. Posiblemente asociado a procesos reparativos mediado por citoquinas

Degeneración y pérdida del cartílago. Usualmente en áreas de carga de peso o elevado estrés. Puede estar ausente cuando existe perdida focal del cartílago.

Depósito de nuevo hueso en respuesta a cambios en la transmisión de fuerza y a causa de micro fracturas del hueso trabecular. Corresponde a áreas de máximo estrés. Esclerosis clínicamente significativa a menudo corresponde a una perdida completa del cartílago articular

Cambio poco común de patogénesis incierta, posible necrosis por presión por el líquido sinovial contra el acceso de vías fisuradas del plato subcondral o relacionada a necrosis por presión a causa de trauma al hueso

Desintegración de la superficie articular u Osteofito fracturado. Puede estar presente generando lesión. Respuesta articular a una avanzada degeneración. 


\subsubsection{Gammagrafía}

Mientras la radiografía (y técnicas relacionadas, incluyendo la tomografía computarizada) proveen considerables detalles anatómicos de cambios óseos en articulaciones afectadas, la gammagrafía provee información fisiológica actual del metabolismo óseo (Caron, 2011). La especificidad de la gammagrafía es baja y una "mancha caliente" podría significar trauma u osteomielitis. Por otro lado, la sensibilidad es alta (McIlwraith, 2004). Continuos cambios en el hueso subcondral se han propuesto a contar del desarrollo tardío de fracturas o OA, los cambios tempranos deberían ser solo visibles con gammagrafía (Ross y Stacy, 2011a).

La gammagrafía puede ser usada en casos en que las pruebas de flexión y analgesia regional no han sido útiles para localizar el origen de la cojera. Una desventaja de la gammagrafía es que su absorción puede estar medianamente incrementada en casos crónicos o progresivos, haciendo difícil la interpretación (Kidd et al, 2001).

\subsubsection{Resonancia magnética}

Las imágenes obtenidas por resonancia magnética son similares a las obtenidas en la tomografía computarizada, proporcionando un muy buen detalle de los tejidos blandos y las estructuras intraarticulares, información que actualmente solo era obtenida por artroscopia (McIlwraith, 2004). Estudios de resonancia magnética de articulaciones de equinos se han limitado ampliamente a cadáveres y piezas anatómicas (Caron, 2011).

\subsubsection{Ultrasonido}

El principal beneficio de un examen ultrasonográfico sobre la radiografía convencional es la superioridad en demostrar las anormalidades de los tejidos blandos como vaina sinovial, cápsula articular, daño intraarticular y ligamentos periféricos articulares (Caron, 2011). La técnica implica un cuidadoso aprendizaje y conocimiento de la anatomía (McIlwraith, 2004). La indicación para examinación ultrasonográfica de la articulación en equinos incluye distención por liquido sinovial, hinchazón local, dolor a la manipulación pasiva de la articulación o analgesia peri neural y hallazgos radiológicos y gamma gráficos positivos (Denoix, 2011). Aunque el ultrasonido no puede penetrar la corteza, las características de la superficie ósea pueden ser evaluadas, incluyendo osteofitos periarticulares y entesófitos, fragmentos osteocondrales e irregularidades del plato subcondral (Caron, 2011).

\subsubsection{Tomografía computarizada}

La gran ventaja de la tomografía computarizada es la detallada evaluación de la estructura ósea. La eliminación de la superposición de estructuras permite al médico detectar pequeños cambios en la densidad ósea causado por procesos de Osteolisis o proliferación que podría pasar inadvertida en la radiografía (Puchalski, 2011).

\subsubsection{Artroscopia}

La cirugía artroscópica es el avance más importante y uno de los más importantes métodos diagnósticos de la enfermedad articular en equinos, esta técnica posee una alta sensibilidad y especificidad (Ross. 2011b). El uso de artroscopia para la examinación de articulaciones supone ventajas tales como la reducción del trauma a ser realizado mediante pequeñas incisiones y disminuye el riesgo de daño a tejidos blandos articulares, mínimos riesgos de complicaciones como dehiscencia y seroma, permite un rápido retorno al trabajo del equino y es más versátil permitiendo el acceso a articulaciones que son difíciles de abordar con otros métodos diagnósticos como la articulación coxofemoral (Ross. 2011b). La artroscopia permite la visualización directa del cartílago, sinovia, ligamentos intra-articulares y es más sensible en la identificación de leve a moderada degeneración del cartílago (Kidd et al, 2001).

\subsubsection{Biomarcadores}

Cuando la homeostasis normal del metabolismo articular se encuentra alterada, un número de macromoléculas liberadas al líquido sinovial presentan concentraciones alteradas respecto a una 
articulación normal. Estos marcadores pueden indicar reparación, síntesis, degradación, incremento óseo, sinovitis y consecuentemente pueden ser usados para cuantificar estos procesos (Kidd, 2001). El trabajo con biomarcadores de cartílago articular y huesos en humanos y caballos con OA ha llevado a resultados promisorios (Frisbie, 2011).

Debido a que las alteraciones bioquímicas causadas por OA involucran procesos dinámicos dentro de todos los componentes de la articulación, estos mediadores bioquímicos y productos del metabolismo de tejido son originados en el cartílago, membrana sinovial y hueso subcondral (Frisbie et al, 2008)

Los biomarcadores pueden ser usados para clarificar procesos patobiológicos en la articulación, realizar diagnostico diferenciales entre articulaciones afectadas y no afectadas y distinguir el grado de degradación en el cartílago articular, monitorear la respuesta al tratamiento y dar un pronóstico (Frisbie et al, 2008).

Los biomarcadores directos específicamente identifican un proceso molecular conocido dentro de un tejido (Frisbie, 2011). Los Biomarcadores directos del catabolismo del cartílago están relacionados a los procesos de degradación del cartílago y consisten principalmente en los productos de ruptura del colágeno tipo II y fragmentos de proteoglicanos que son liberados en grandes concentraciones al fluido sinovial (Mcllwraith, 2005b). Los Biomarcadores de la fase anabólica corresponden a proteínas producidas activamente por osteoblastos y condrocitos (Frisbie, 2011).

Los marcadores moleculares indirectos reflejan cambios más generales que no están claramente definidos y pueden contribuir en varios eventos y tejidos. Son marcadores indirectos citoquinas, factores de crecimiento y MMPs (Frisbie, 2011).

Biomarcadores de procesos anabólicos del cartílago articular: El Pro péptido tipo II del procolágeno (CPII), es usado para medir el proceso de síntesis del colágeno tipo II (Frisbie, 2011).

El condroitin sulfato (CS) es el mayor GAGs de los agreganos (Frisbie, 2011). El epitopo 846 de CS (CS-846) es normalmente encontrado en cartílagos en OA y se encuentra ausente en cartílago sano y cartílago articular maduro (Berg-Johansson, 2009). Se cree que el epitopo 846 eleva sus concentraciones en articulaciones afectadas debido a que su producción se ha observado ligada al incremento en la producción de agrecanos, que es alta en OA (Kidd, 2001). CS-846 es muy usado para la diferenciación temprana entre articulación normal y OA (Berg-Johansson, 2009).

Biomarcadores de procesos catabólicos del cartílago articular: incluyen la medición de la degradación del colágeno tipo II, que provee una beneficiosa forma de monitorear OA y osteocondritis disecante (OCD) (McIlwraith, 2005b). Elevaciones significativas en las concentraciones de colágeno tipo II degradado han sido demostradas en el líquido sinovial y muestras de suero de caballos, perros y conejos con OA experimental (McIlwraith, 2005b).

Matriz proteica oligomérica de cartílago (COMP) es una abundante proteína no colagenosa constituyente del cartílago. Se creía que era específica del cartílago pero también se ha observado en tendones y sinovia (McIlwraith, 2005b). Una correlación positiva existe entre COMP y gradientes radiológicos de OA, progresión de cambios radiológicos y resultado de cintigrafía nuclear en humanos (Frisbie, 2011). Solo COMP intacta se encontró presente en líquido sinovial de articulaciones con fracturas osteocondrales, mientras, COMP fragmentada fue encontrada prominentemente en el líquido sinovial de articulaciones con OA (Berg-Johansson, 2009).

Biomarcadores del metabolismo óseo: incluyen marcadores de procesos anabólicos y catabólicos, pero no está clara su concentración en un hueso normal y enfermo (Frisbie, 2011). Osteocalcina (OCa) es una pequeña proteína no colagenosa asociada a la formación y mineralización ósea (Berg-Johansson, 2009). Sin embargo, la concentración de OCa en el suero es mayor que en el líquido sinovial, por lo que OCa en 
el líquido sinovial puede ser derivado desde la sangre periférica y no reflejar la enfermedad articular local (Frisbie, 2011).

La fosfatasa alcalina ósea especifica (BAP) es otro biomarcador de procesos anabólicos óseos. Corresponde a una isoforma de la fosfatasa alcalina, expresada en altas concentraciones en la superficie celular de osteoblastos que forman el hueso, BAP juega un rol importante en la formación del hueso (McIlwraith, 2005b). Una correlación positiva fue encontrada entre BAP del líquido sinovial y el daño del cartílago articular demostrando una unión entre los cambios del hueso y cartílago articular en OA (BergJohansson, 2009).

Biomarcadores de procesos catabólicos óseos: se incluye el Colágeno tipo I C-telopeptido (CTX), que puede ser usado como marcador de resorción ósea (Frisbie, 2011). En un estudio evaluando la habilidad de biomarcadores séricos para diferenciar ejercicio de patología y correlación de biomarcadores con parámetros clínicos de dolor en modelos de OA, CTX fue el biomarcador menos eficiente respecto a biomarcadores de cartílago (CS-846, CPII y GAG) (McIlwraith, 2005b).

La Sialoproteina ósea es encontrada solamente en hueso adulto y su concentración es siete veces más alta en la interface cartílago hueso comparado con el hueso propiamente (Mcllwraith, 2005b). La Sialoproteina ósea equina ha sido caracterizada pero el desarrollo de una evaluación es actualmente lejana. Se espera que ésta pueda ser usada en la identificación del daño del hueso subcondral en caballos con OA (Frisbie, 2011).

Los Biomarcadores indirectos: incluyen IL-6, TNF- $\alpha$ y IL-1 $\beta$. Según McIlwraith (2005b), la IL-6 es más sensible y específico, mientras TNF- $\alpha$ y IL- $1 \beta$ son menos usados que el recuento de células blancas en las pruebas de enfermedad articular.

5. Tratamiento

El abordaje médico de OA debe seleccionar el tratamiento que trabaje de mejor forma en el miembro y articulación afectada. El objetivo del tratamiento temprano de OA se enfoca en inhibir los cambios degenerativos, una terapia temprana y enfocada a tratar la inflamación, podría reducir estos cambios degenerativos (Goodrich y Nixon, 2006). Además de reducir el grado de cojera y retornar el caballo al trabajo, la supresión de la sinovitis y capsulitis son manejos importantes para prevenir que los productos de inflamación comprometan el cartílago articular y causen OA (McIlwraith, 2011).

\subsection{Corticoides intra-articulares}

Los cortico esteroides son en su mayoría, la droga más comúnmente usada para tratamiento intraarticular de sinovitis no infecciosa, con un potente efecto anti-inflamatorio y actividad analgésica indirecta (Grauw et al, 2015). Se describen en algunos reportes efectos adversos del uso de corticoides en el cartílago articular tales como disminución del tamaño de condrocitos, pérdida de GAGs y disminución de la síntesis de GAGs, inhibición de la síntesis de proteoglicanos, necrosis de condrocitos e hipocelularidad asociada al sobre uso de estos fármacos (Goodrich y Nixon, 2006).

Algunos problemas asociados a la administración intra-articular de corticoides son descritos por Goodrich y Nixon en 2006:

- Artropatía esteroidal: se presenta en caballos con severa OA seguida de repetidas inyecciones de cortico esteroides combinada con ejercicio continuo. Esta condición presenta una baja incidencia, pudiendo manifestarse como una progresión normal u acelerada de OA como efecto directo de la terapia con cortico esteroides. Los cambios observados son pérdida del espacio articular, signos de inestabilidad articular y osteo-necrosis.

- Inflamación pos inyección: esta secuela ha sido reportada con una incidencia de >2\%, usualmente es una condición auto-limitante. Se cree que la naturaleza de la inflamación es causada por las 
características de micro cristales de los cortico esteroides, la dosis y el corticoide en particular inyectado.

- Potenciación de infecciones: esto es de gran preocupación para los médicos veterinarios, sin embargo, la incidencia es baja. Se deben considerar estrictas medidas de asepsia al realizar una inyección intra-articular. La bacteria más comúnmente aislada es Staphylococcus aureus.

En el Tabla 5 se indican los cortico esteroides más usados en equinos y sus dosis (adaptado de Goodrich y Nixon, 2006).

\section{2. Ácido hialurónico}

Teóricamente, la acción de hialuronato sódico en el líquido sinovial es restaurar la viscoelasticidad y lubricar los tejidos blandos articulares, además, estudios in vitro identificaron efectos adicionales como la inhibición de la quimiotaxis de macrófagos, reducción de la habilidad de los linfocitos para proliferar y migrar, disminuir la formación de prostaglandinas en macrófagos durante la fagocitosis y limpiar radicales libres de oxígeno (Goodrich y Nixon, 2006). El hialuronato tiene un modesto efecto analgésico, sin embargo, mayor énfasis se ha dado a su capacidad anti-inflamatoria que puede ser física (bloqueo estérico) o farmacológica (inhibición de células y mediadores inflamatorios) (McIlwraith, 2011). Se ha sugerido que los efectos anti-inflamatorios del hialuronato son el resultado de la menor interacción de enzimas, antígenos o citoquinas con las células blancas a través de una barrera estérica (McIlwraith, 2004). Sin embargo, se ha sugerido recientemente que la reducción de la quimiotaxis y fagocitosis de neutrófilos activados está mediado a través de la interacción del hialuronato con receptores CD44 presentes en la membrana de neutrófilos (Goodrich y Nixon, 2006).

Tabla 5. Fármacos comúnmente usados, dosis y duración del efecto.

\begin{tabular}{lll}
\hline Cortico esteroide & Dosis $(\mathrm{mg})$ & Duración \\
\hline Acetato betametasona & $3-18$ & Media a larga \\
Acetato de metilprednisolona & $40-100$ & Larga \\
Flumetasona & $1,25-2,5$ & Larga \\
Acetonido de triamcinolona & $6-18$ & Media \\
Isoflupredona & $4-20$ & Corta a media \\
\hline
\end{tabular}

Un efecto del hialuronato sobre la reparación del cartílago incluyen agregación de proteoglicanos en vitro, sin embargo no hay datos convincentes que apoyen los efectos que tiene el hialuronato exógeno sobre la agregación de los proteoglicanos in vivo (McIlwraith, 2004).

La administración de hialuronato endovenoso es una forma no invasiva de administración y una forma para tratar múltiples articulaciones al mismo tiempo. Los efectos beneficiosos se deben probablemente a su localización en la membrana sinovial dado que la vida media plasmática no es mayor a 5 minutos (Goodrich y Nixon, 2006). Se cree que el mecanismo por el cual el hialuronato endovenoso ejerce su efecto se asocia a su localización en la articulación, puesto que, la membrana sinovial del caballo se encuentra muy vascularizada, es probable que la administración intravenosa proporcione a los sinoviocitos una mayor exposición al hialuronato exógeno que cuando se aplica por vía intra-articular (McIlwraith, 2004). 
La combinación de hialuronato y cortico esteroides es común. Sin cortico esteroides, la eficacia de la inyección intra-articular de hialuronato es limitada a caballos con leve a moderada sinovitis (McIlwraith, 2011). Sin embargo, Grauw y col (2015) realizaron un estudio comparando el uso de triamcinolona versus triamcinolona y hialuronato, ambos administrados por vía intra-articular, en el cual indican la reducción de cojera más de 2 grados en pacientes tratados solamente con triamcinolona por sobre los tratados con terapia combinada, además, indican que la mitad de los pacientes volvieron al trabajo a los 3 meses independientemente del tratamiento utilizado.

\subsection{Glicosaminoglicanos sulfatados (GAGst)}

Generalmente se hace referencia a este grupo por tener propiedades condroprotectoras y debido a esto se utilizan comúnmente cuando se considera el cartílago dañado más que para el tratamiento de sinovitis (McIlwraith, 2004). Siguiendo la nueva nomenclatura, los GAGst debiesen considerarse drogas osteoartrosicas modificadoras de la enfermedad (McIlwraith, 2011). El tratamiento con estos medicamentos da lugar a la prevención, retraso o reversión de las lesiones cartilaginosas de la osteoartritis, siendo el principal criterio de inclusión, la prevención de la destrucción del cartílago (McIlwraith, 2004)

Se ha observado que GAGst inhiben una amplia gama de enzimas de degradación que contribuyen al proceso de OA (Goodrich y Nixon, 2006). El rol anti-inflamatorio está basado en el efecto inhibitorio en la migración de leucocitos y niveles de interleuquinas (Goodrich y Nixon, 2006). Algunos trabajos mencionados por McIlwraith (2004) indican que GAGst tienen actividad anti IL-1 y PGE 2 , además de los efectos anti degradantes los GAGst estimulan la síntesis de hialuronato tanto in vivo como in vitro.

La administración oral de GAGst contiene componentes de cartílago y precursores moleculares tales como condroitin sulfato y glucosamina. Cuando glucosamina (GS) es suministrado de forma exógena resulta en una elevación de las concentraciones intracelulares de UDP- $N$-acetilglucosamina, componente crítico en la formación de GAGs encontrados en el cartílago como hialuronato, sulfato de heparina y sulfato de keratina (McIlwraith, 2004). El efecto antiinflamatorio de la GS incluye inhibición de proteasas, óxido nítrico y metaloproteinasas, modificación de la actividad de colagenasas y PLA 2 , inhibición de IL-1 $\beta$ y metaloproteinasas de matriz (Goodrich y Nixon, 2006).

El condroitin sulfato (CS) contribuye al depósito de sustrato para la matriz, inhibe proteasas, estimula GAG y síntesis de colágeno, mejora la viscosidad del líquido sinovial por incremento de hialuronato. Se propone que la combinación de CS y GS es una combinación sinérgica, su efecto condroprotector es mucho mayor que al ser usados por separado (Goodrich y Nixon, 2006).

El Adequan, una droga de origen animal, está aprobado para su administración por vía IM e IA (Goodrich y Nixon, 2006). La administración IM de GAGst se realiza frecuentemente, sin embargo, la inyección intramuscular de GAGst produce efectos relativamente insignificantes en caballos con sinovitis inducida (McIlwraith, 2011). Actualmente, poca evidencia justifica la administración intramuscular de GAGst (Goodrich y Nixon, 2006). Por otro lado, la administración intra-articular ha sido respaldado por varios estudios en equinos con $\mathrm{OA}$, incluyendo un estudio clínico. La principal utilidad de la administración por vía intra-articular de GAGst corresponde a los casos severos y agudos de sinovitis, sin embargo, no se debe inyectar una articulación activamente inflamada por lo que un tratamiento antiinflamatorio debiese priorizarse antes que la inyección intra-articular (McIlwraith, 2011).

\subsection{Reposo, inmovilización y rehabilitación}

La utilidad del reposo en los pacientes con inflamación aguda y lesión capsular es obvia, sin embargo, la realidad de las carreras u otras actividades atléticas a menudo impide la aplicación apropiada de esta modalidad, que permitiría una recuperación completa en muchos casos (McIlwraith, 2004).

El principio básico del reposo es reducir la fuerza y estrés en el tejido dañado y permitir que los procesos reparativos normales procedan. El músculo puede sanar más rápido que los tendones y 
ligamentos, por otra parte, la reparación del cartílago es complicada debido a la metaplasia del tejido al repararse, que toma alrededor de 4 a 6 meses. Por lo tanto, la calidad y cantidad del reposo depende de la severidad de la condición, el tejido afectado, el temperamento del caballo y el dueño u entrenador (Grant, 2011).

La pausa de la actividad deportiva es la forma más comúnmente recomendada de reposo y es altamente efectiva, siempre y cuando se haga en largos períodos fuera de actividad en forma ininterrumpida (Grant, 2011). Controversialmente, el mismo autor menciona que existe una discusión en la realización de ejercicio de forma pasiva, ya que el ejercicio podría ser beneficioso en la mantención de las concentraciones normales de GAGs en el cartílago dañado.

Grant (2011) indica que largos períodos de inmovilización puede resultar en osteoartritis y osteopenia, además señala que una articulación normal puede tolerar hasta 4 semanas de inmovilización sin cambios significativos e irreversibles del cartílago articular. Según señala Dittmer y Teasell (1993) la cápsula articular contracturada y la inmovilización de la articulación en una posición fija provoca largos períodos de compresión del cartílago en los sitios de contacto con su subsecuente degeneración.

La inmovilización es importante cuando hay cualquier tipo de lesión desestabilizante pero no es lo ideal si el problema está limitado a una sinovitis/Capsulitis puesto que la inmovilización prolongada puede conducir a la atrofia muscular y a la formación de adherencias dentro de la articulación, así como también la atrofia del cartílago articular (McIlwraith, 2004).

En la rehabilitación, el ejercicio es un componente básico que tiene como objetivo volver al caballo a su performance previo al daño (Grant, 2011). Se recomienda realizar flexión pasiva del miembro afectado para conservar la movilidad (McIlwraith, 2004). Los ejercicios pasivos proveen la distribución de nutrientes a los condrocitos y reducen el número de adhesiones sinoviales. La articulación debiese ser flectada hasta el punto álgido 15 a 20 veces, 2 veces al día, durante 30 días (Grant, 2011). La realización de caminatas lentas debiese continuar aun cuando el entrenamiento se detenga, estas caminatas mantendrán el movimiento de la cápsula articular y evitarán cambios atróficos en el cartílago articular (McIlwraith, 2004). Se indica que después de haber realizado un reposo con cese total de actividades deportivas por 30 días, se debe comenzar a realizar caminatas 5 a 10 minutos al día por otros 30 días y subir gradualmente a 30 minutos (McIlwraith, 2011).

Se ha reportado que el nado mejora la fuerza muscular y coordinación, disminuye el edema, mejora el rango de movimiento articular y disminuye el dolor, debido a la reducción del estrés mecánico aplicado al miembro (King et al, 2012).

\subsection{Anti inflamatorios no esteroidales (AINES)}

El termino AINES hace referencia a un grupo de fármacos anti-inflamatorios que inhibe algún componente del sistema enzimático que convierte el ácido araquidónico en prostaglandinas y tromboxanos (Goodrich y Nixon, 2006). En algunas especies, los efectos tóxicos de los AINES, en particular úlceras gástricas están muy descritas. Interesantemente, la toxicidad en equinos se ha observado de forma muy poco frecuente si el AINES es administrado den la dosis clínica recomendada (McIlwraith, 2004).

La Fenilbutazona (FBZ) es el AINES más comúnmente usado para el manejo de inflamaciones músculo esqueléticas y dolor en caballos, particularmente en OA (Barton, 2015). Sorpresivamente, pocas investigaciones se han realizado sobre los efectos clínicos que tiene la FBZ sobre la enfermedad articular (Mcllwraith, 2011). Goodrich y Nixon (2006) mencionan que existe inhibición de la síntesis de proteoglicanos in vivo asociado a la administración de FBZ, por el contrario Frean y col (2002) mencionan que el fármaco no interfiere con la síntesis de proteoglicanos.

La FBZ comúnmente es comparada con otros AINES. Por ejemplo, flunixin meglumine y FBZ parecen tener un efecto analgésico similar en caballos con síndrome navicular. Sin embargo, FBZ es más 
efectivo en cuanto a duración del efecto y reducción del grado de cojera, temperatura articular, y volumen del líquido sinovial que el ketoprofeno (Barton, 2015). Se ha observado que FBZ puede aplicarse a 2,2 $\mathrm{mg} / \mathrm{kg} 2$ veces al día, aunque, debido a su extendida duración en exudados inflamatorios ( 24 horas), una sola dosis de 4,4 mg/kg día podría ser suficiente (Goodrich y Nixon, 2006). Aunque FBZ es un inhibidor de la ciclooxigenasa como muchos otros AINES, inhibe la síntesis de prostaglandinas a una dosis mucho más baja que aquellas requeridas para suprimir el edema o el acumulo leucocitario en los focos inflamatorios.

\subsection{Terapias regenerativas}

El objetivo de la terapia regenerativa articular es restaurar la estructura normal y fisiológica de la superficie articular, hueso subcondral, ligamentos, meniscos, membrana sinovial y otras estructuras alrededor de la articulación afectada, dañadas por trauma, degeneración o procesos inflamatorios (Sandoval et al, 2013).

\subsubsection{Terapia génica}

La terapia génica intenta introducir genes a células articulares que están altamente asociadas con el proceso patológico, por ejemplo condrocitos, sinoviocitos y leucocitos (Evans et al, 2004). Teóricamente, la introducción de los genes apropiados a las células articulares permiten incrementar la producción de moléculas anabólicas como factores de crecimiento, IGF-1, proteína morfo genética 8, citoquinas antiinflamatorias como la antagonista de receptor de IL-1 (IL-1 ra), IL-10, IL-4 (Sandoval et al, 2013).

Los tejidos articulares que pueden ser usados como blanco para la transferencia de genes incluyen la membrana sinovial, cartílago articular y meniscos. Sin embargo, la membrana sinovial es la mejor alternativa debido a su amplia superficie y contacto con el espacio articular, siendo usada para introducir genes de antagonista de receptores de IL-1 (McIlwraith y Frisbie, 2011).

Para el manejo de OA se realiza la administración intra-articular de la proteína de IL-1ra, la máxima duración de producción de IL-1 ra fueron 35 dias. Los caballos que han sido tratados con la proteína de IL1ra muestran una marcada reducción de la erosión del cartílago, bajo score inflamatorio, reducción en la incidencia de osteofitos, expresión de MMP-1 (McIlwraith y Frisbie, 2011).

\subsubsection{Células tronco}

Las actuales terapias regenerativas con células tronco mesenquimales (MSC) en caballos utilizan células tronco derivadas de medula ósea para el tratamiento de tendinopatías y células tronco derivadas de medula ósea o tejido adiposo para el tratamiento de OA (Spaas et al, 2012).

El objetivo actual de la terapia es la diferenciación condrogénica de las MSC basado en el conocimiento del desarrollo condrogénico, función y homeostasis del cartílago (Sandoval et al, 2013). La mayoría de las experiencias clínicas con el uso de MSC en caballos provienen del tratamiento de tendones y ligamentos dañados; en el caso del cartílago articular pocos estudios se han realizado con resultados controversiales (Sandoval et al, 2013). Sin embargo, en un estudio realizado en cabras donde se aplicó MSC, la degeneración del cartílago articular, remodelación del hueso subcondral, formación de osteofitos y esclerosis subcondral fueron reducidas después del tratamiento (Mobasheri et al, 2009).

\subsubsection{Plasma rico en plaquetas}

El plasma rico en plaquetas es un concentrado natural de factores de crecimiento (FC) autólogos obtenidos desde la sangre, es fácil de realizar, bajo costo, y la obtención de la muestra es mínimamente invasiva (Hassan et al, 2015). 
Las plaquetas son una fuente de FC y otras proteínas que estimulan la reparación tisular, reducen la inflamación, inducen quimiotaxis en células mesenquimales, causan proliferación celular y diferenciación celular y favorecen la neo vascularización y depósito de MEC (Sandoval et al, 2013).

Los factores de crecimiento angiogénicos como VEGF, HGF y PDGF incrementan la vascularización del tejido con un aumento subsecuente del metabolismo de las células constitutivas. PDGF y TGF- $\beta_{1}$ son quimiotaxicos para células tronco, particularmente en la membrana sinovial, estas proteínas además, inducen la diferenciación de estas células a condrocitos. Finalmente, TGF- $\beta_{1}$, PDFG y IGF-1 actúan como anti-inflamatorios y proteínas anabólicas con directa regulación de NF-kb (Sandoval et al, 2013).

\section{CONCLUSIONES}

La osteoartritis, conocida antiguamente como enfermedad degenerativa articular, es una enfermedad que causa grandes pérdidas a la industria equina, considerando la baja de rendimiento deportivo, gastos médicos implicados en el diagnóstico y tratamiento, cuidados del animal y tiempo empleado en esto. El costo médico y quirúrgico de cojeras relacionadas a OA fue mayor a 700 millones de dólares en EEUU.

Para quien practica la medicina equina es muy importante el conocimiento de la fisiología articular y fisiopatología de OA, debido a que son los mismos procesos fisiológicos catabólicos y anabólicos articulares, que al sufrir un desbalance en el equilibrio de mantención del cartílago articular causan su degradación. Las causas de OA son diversas, pero todas convergen en la misma finalidad, la degradación del cartílago articular, es por esto que los métodos diagnósticos como biomarcadores son herramientas útiles para el diagnóstico temprano de la enfermedad y así mejorar el pronóstico de sobrevida y deportivo del animal evitando así el diagnóstico tardío mediante radiografía, en la cual los signos radiográficos no guardan relación con la representación clínica de la enfermedad y evitar los problemas de bienestar animal causados por el dolor crónico. Métodos avanzados como resonancia magnética son de gran utilidad para evaluar el conjunto estructural que supone una articulación, lamentablemente no existe una maquinaria específica para equinos que facilite la utilización y diagnóstico.

El tratamiento de OA está enfocado al retraso de los cambios degenerativos, además de tratar la sintomatología, lamentablemente al ser una enfermedad degenerativa en conjunto con un diagnóstico tardío reducen las alternativas terapéuticas que prolonguen y mejoren el pronóstico deportivo de los caballos. El objetivo terapéutico de la OA debería comenzar a enfocarse en tratar la inflamación de forma temprana puesto que es esta la que desencadena todos los procesos degenerativos que llevan a la destrucción de la articulación, controversialmente, la alternativa terapéutica más utilizada para el tratamiento de OA, la inyección intra articular con corticoides, posee efectos adversos que a pesar de su baja incidencia, si se utiliza de forma continua y desmesurada puede llevar a aumentar la velocidad con la que se desarrolla la enfermedad reduciendo el pronóstico y tiempo de vida deportiva del caballo. El desarrollo de nuevas alternativas terapéuticas como son las terapias regenerativas, entregan resultados controversiales en los cuales en algunos estudios se demuestra que funcionan y otros indican escasa o ninguna acción, quizás determinado por la variabilidad caso a caso de la OA, grado de degeneración del cartílago articular, severidad del proceso inflamatorio o corrección de factores predisponentes. 
Sustainability, Agri, Food and Environmental Research 4(2), 2016: 16-37

ISSN: 0719-3726

\section{REFERENCIAS}

Aigner, T., Schmitz, N. 2011. Pathogenesis and Pathology of Osteoarthritis. In: Rheumatology. Fifth Ed. Saunder Elsevier. Pp 1741 - 1759

Baxter, G. 2011. Fundamentals of Lameness Diagnosis. In: Manual of Equine Lameness. First ed. Wiley Blackwell. Pp $65-82$.

Barton, M. 2015. Non-steroidal Anti-inflammatories. In: Equine Clinical Inmunology. First ed. Wiley Blackwell. Pp 213 - 233

Bertone, A., 2008. Joint Physiology: Responses to Exercise and Training. In: Equine Exercise Physiology the Science of Exercise in the Athletic Horse. First ed. Saunder Elsevier. Pp 132 -142

Berg-Johansson, J. 2009. Biomarkers in Equine Bone and Joint Disorders. Thesis. Bachelor's degree. Swedish University of Agricultural Sciences.

Björnsdóttir, S., Axelsson, M., Eksell, M., Sigurdsson, H., Carlsten, J. 2000. Radiographic and Clinical Survey of degenerative Jpint Disease in the Distal Tarsal Joint in Icelandic Horse. Equine Veterinary Journal 32 (3); pp 268 - 272

Caron, J. 2011. Arthritis: Osteoarthritis. In: Diagnosis and Management of Lameness in the Horse. Second Ed. Saunder Elsevier, St Louis, MO, USA. Pp 655-668.

Carmona, J., Prades, M. 2009. Pathophysiology of Osteoarthritis. Compendium Equine: Continuing Education for Veterinarians; 28 - 40

De Grauw JC, Molecular monitoring of equine joint homeostasis. Thesis, Utrecht University, 2010

Denoix, J. 2011. Ultrasonographic Examination of Joints. In: Diagnosis and Management of Lameness in the Horse. Second Ed. Saunder Elsevier, St Louis, MO, USA. Pp 239 - 245

Dieppe, P., Lohmander, S. 2005. Pathogenesis and Managemento of Pain in Osteoarthritis. The Lancent 365; Pp 965-973

Dittmer, D., Teasell, R. 1993. Bed Rest, Part 1: musculoskeletal and cardiovascular complication. Canadian Family Physician 39; 1428-1437

El-Gabalawy, H. 2013. Synovial Fluid Analysis, Synovial Biopsy, and Synovial Patology. In: Kelley's Textbook of Rheumatology. Novena Ed. Saunder Elsevier. Pp 753 - 769

Evans, CH., Gouze, JN., Gouze, E., Robbins, PD., Ghivizzani, SC. 2004. Osteoarthritis Gene Therapy. Gene Therapy 11, 379 - 389

Fernandez, J., Mertel-Pelletier, J., Pelletier, J. 2002. The Role of Cytokines in Osteoarthritis. In: Mechanobiology: Cartilage and Chondrocyte Vol 2. IOS Press. 237- 258.

Frean, S., Cambridge, H., Lees, P. 2002. Effects of Anti-arthritic Drugs on Proteoglycan Synthesis by Equine Cartilage. Journal Veterinary Pharmacology and Therapeutics 25; Pp 289-298.

Frisbie, D., Al-Sobayil, F., Billinghurst, C., Kawcak, E., McIlwraith, W. 2008. Changes in Synovial Fluid and Serum Biomarkers with Exercise and Early Osteoarthritis in Horse. Osteoarthritis and Cartilage 16; $1196-1204$ 
Frisbie, D. 2011. Makers of Osteoarthritis: Implications for Early Diagnosis and Monitoring of the Pathological Course and Effects of Therapy In: Diagnosis and Management of Lameness in the Horse. Second Ed. Saunder Elsevier, St Louis, MO, USA. Pp 668 - 671.

Frisbie, D. 2012. Synovial joint Biology and Pathobiology. In: Equine Surgery. Fourth ed. St Louis. Saunder Elsevier. Pp 1096 - 1113

Frisbie, D., McIlwraith, C., Kawcak, C., Werpy, N. 2013. Evaluation of Intra-articular Hyaluronan, Sodium Chondroitin Sulfate and N-acetil-D-Glucosamine Combination Versus Saline $(0.9 \% \mathrm{NaCl})$ for Osteoarthritis Using an Equine Model. The Veterinary Journal 197 ; Pp 824-829

Goodrish, L., Nixon, A. 2006. Medical Treatment of Osteoarthritis in the Horse - A Review. The Veterinary Journal 171; 51-69

Grant, B. 2011. Rest and Rehabilitation. In: Diagnosis and Management of Lameness in the Horse. Second Ed. Saunder Elsevier, St Louis, MO, USA. Pp 877-880.

Grauw, J., Visser-Meijer, M., Lashley, F., Meeus, P., Weeren, P. 2015. Intra-articular Treatment with Triamcinolone Compared with Triamcinolone with Hyaluronato: A Randomised Open-label Multicentre Clinical Trial in 80 lame Horse. Equine Veterinary Journal. doi: 10.1111/evj.12383

Hashimoto, S., Creighton-Achermann, L., K. Takahashi, K., Amiel, D,. Coutts, R., Lotz, M. 2002. Development and Regulation of Osteophyte Formation during Experimental Osteoarthritis. Osteoarthritis and Cartilage 10; 180-187

Hassan, A., El-Shafey, A., Ahmed, H., Hamed, M. 2015. Effectiveness of the Intra-articular Injection of Platelet Rich Plasma in the Treatment of Patients with Primary Knee Osteoarthritis. The Egyptian Rheumatologist 37; 119-124.

Hayami, T., Pickarski, M., Wesolowski, G., Mclane, J., Bone, A., Destefano, J., Rodan, G., Duong, L. 2004. The Role of Subchondral Bone Remodeling in Osteoarthritis. Arthritis \& Rheumatism 50; pp 1193 1206

Johnston, S. 1997. Osteoarthritis Joint Anatomy, Physiology, and Pathobiology. Veterinary Clinics of North America: Small Animal Practice 27 (4); 699 -723

Kidd, J., Fuller, C., Barr, A. 2001. Osteoarthritis in the Horse. Equine Veterinary Education 13 (3), Pp 160 $-168$

Kim D. 2002. Role of Chondrocyte Apoptosis in the Pathogenesis of Equine Osteoarthritis. Thesis, Doctor of Philosophy. Louisiana State University.

King, M., Haussler, K., Kawcak, C., McIlwraith, C., Reiser, R. 2012. Mechanisms of aquatic Therapy and its Potential Use in Managing Equine Osteoarthritis. Equine Veterinary Education 25 (4), Pp 204-209.

Kraus, V., Blanco, F., Englund, M., Karsdal, M., Lohmander, L. 2015. Call for Standardized Definitions of Osteoarthritis and Risk Stratification for Clinical Trials and Clinical Use. Osteoarthritis Research Society International. Pp 1233- 1241.

Ley C, S Ekman, B Ronéus, M Eloranta. 2009. Interleukin-6 and high mobility group box protein-1 in synovial membranes and osteochondral fragments in equine osteoarthritis. Res Vet Sci 86, 490-497.

Li, G., Yin, J., Gao, J., Cheng, T., Pavlos, N., Zhang, Ch., Zheng, M. 2013. Subchondral Bone in Osteoarthritis: Insight Risk Factors and Microstructural Changes. Arthritis Research \& Therapy 15: 223 
Lynch, T., Caron, J., Arnoczky, S., Lloyd, J., Stick, J., Render, J. 1998. Influence of exogenous hyaluronan on synthesis of hyaluronan and collagenase by equine synoviocytes. American Journal of Veterinary Research 59, $888-892$.

Maninchedda, U., Lepage, O., Gangl, M., Hilairet, S., Remandet, B., Meot, F,. Penairer, G., Segard, E., Cortez, P., Jorgensen, C. et al, 2015. Development of an Equine Groove Model to Induce Metacarpophalangeal Osteoarthritis: A Pilot Study on 6 Horses. PLoS ONE 10(2): e0115089. Doi:10.1371/journal.pone.0115089

Mc Donald L. 2010. Osteoartrosis. En: Smith B (ed).Medicina Interna de Grandes Animales. 4a ed. Elsevier, Madrid, España. Pp 1207-1210.

McIlwraith, C. 2004. Enfermedades de las Articulaciones, Los Tendones, Los Ligamentos y Las Estructuras Relacionadas. In: Adams Claudicaciones en Equinos. Quinta ed. Saunder Elsevier. Buenos aires. Argentina. Pp 469 - 493

McIlwraith, C. 2005a. From Arthroscopy to Gene Therapy - 30 Years of Looking in Joints. Proceedings of the Annual Convention of the AAEP, Seattle, Washington, USA, 65-113.

McIlwraith, C. 2005b. Use of Synovial Fluid and Serum Biomarkers in Equine Bone and Joint Disease: a review. Equine veterinary journal 37 (5); 473 - 482

McIlwraith, C. 2011. Principles and Practices of Joint Disease Treatment. In: Diagnosis and Management of Lameness in the Horse. Second Ed. Saunder Elsevier, St Louis, MO, USA. Pp 840-852.

McIlwraith, C., Frisbie, D. 2011. Gene Therapy. In: Diagnosis and Management of Lameness in the Horse. Second Ed. Saunder Elsevier, St Louis, MO, USA. Pp 671-673.

McIlwraith, C. 2015. Traumatic Arthritis and Posttraumatic Ostearthritis in the horse. In: Joint Disease in the Horse. Second Ed. St Louis. Saunder Elsevier. Pp 33-49

Martel-Pelletier, J., Alaaeddine, N., Pelletier, J. 1999. Cytokines and Their Role in the Pathophysiology of Osteoarthritis. Frontiers in Bioscience 4.

Mele, E. 2007. Epidemiology of Osteoarthritis. Veterinary focus 17 (3).

Mobasheri, A., Csaki, C., Clutterbuck, A., Rahmanzadeh, M., Shakibaei, M. 2009. Mesenchymal Stem Cells in Connective Tissue Engineering and Regenerative Medicine: Applications in Cartilage Repair and Osteoarthritis Therapy. Histology and Histopathology 24; 347-366

Mullen, K., Schwark, W., Divers, T. 2013. Pharmacokinetics of Single-dose Intragastric and Intravenous Pregabalin Administration in Clinically Normal Horse. American journal of veterinary research 47 (7); 1043-1048

Oke SL, McIlwraith CW. 2010. Review of the economic impact of osteoarthritis and oral joint-health supplements in the horse. in Proceedings. 56 AAEP; 56; 12-18.

Palmer J, Bertone AL. 1994. Joint structure, biochemistry and biochemical disequilibrium in synovitis and equine joint disease. Equine Vet J; 26; 263-277.

Puchalski, S. 2011. Computed Tomography. In: Diagnosis and Management of Lameness in the Horse. Second Ed. Saunder Elsevier, St Louis, MO, USA. Pp 269 - 274

Ross, M., Stacy, V. 2011a. In: Diagnosis and Management of Lameness in the Horse. Second Ed. Saunder Elsevier, St Louis, MO, USA. Pp $249-268$ 
Riggs C. 2006. Osteochondral injury and joint disease in the athletic horse. Equine Vet Educ 18, 100-112. Ross, M. 2011b. Arthroscopic Examination. In: Diagnosis and Management of Lameness in the Horse. Second Ed. Saunder Elsevier, St Louis, MO, USA. Pp 289 - 297.

Sandoval, J., López, C., Carmona, J. 2013. Therapies Intended for Joint Regeneration in the Horse. Archivos de medicina veterinaria $45 ; 229-236$

Schlueter, A., Orth, M. 2004. Equine Osteoarthritis: A Brief Review of the Disease and its Causes. Equine and Comparative Exercise Physiology 1 (4); 221 - 231

Spaas, J., Oosterlinck, M., Broeckx, S., Dumoulin, M., Saunder, J., Van Soom, A., Pille, F. 2012. Treatment of Equine Degenerative Joint Disease with Autologous Peripheral Blood-derived Mesenchymal Stem Cell: a case report. Vlaams Diergeneeskundig Tijdschrift 81; 11- 16

Steel, C. 2008. Equine Synovial Fluid Analysis. Veterinary Clinics Equine Practice 24; 437 - 454

Weeren, R. 2014. Joint physiology: responses to exercise and training. In: Equine Sports Medicine \& surgery. Second Ed. Saunder Elsevier. St Louis, MO, USA. Pp 213-222

Van der Kraan, P., Van den Berg, W. 2007. Osteophytes: Relevance and Biology. Osteoarthritis and Cartilage 15; $237-244$. 